\title{
Уважаемые коллеги!
}

Предлагаем вашему вниманию авторский комментарий наших коллег В.Г. Дорофейчук и С.А. Шер, известных ученых в области микробиологии и иммунологии, многие годы своей профессиональной деятельности в СССР, РФ и США посвятивших изучению свойств и внедрению в реальную клиническую практику удивительного и, возможно, недооцененного вещества лизоцима. В данном обзоре авторы излагают не только свою точку зрения на возможный механизм реализации новой коронавирусной инфекции, но и предлагают доступные решения помощи этим пациентам. Данным коротким сообщением мы хотели бы открыть дискуссию по этой очень интересной теме и приглашаем вас, дорогие читатели, присылать нам ваши комментарии.

\section{В.Г. Дорофейчук, С.А. Шер}

НИИ педиатрии и охраны здоровья детей ЦКБ РАН Министерства науки и высшего образования РФ, Москва, Российская Федерация

\section{Концепция возникновения новой коронавирусной инфекции}

Автор, ответственный за переписку:

Шер Стелла Абельевна, доктор медицинских наук, главный научный сотрудник НИИ педиатрии и охраны здоровья детей ЦКБ РАН Министерства науки и высшего образования РФ

Адрес: 119333, Москва, ул. Фотиевой, д. 10, стр. 1, тел.: +7 (915) 438-69-14, e-mail: anastel@mail.ru

В данном сообщении представлены краткий обзор литературы и авторская концепция возникновения новой коронавирусной инфекции. Цель работы - основываясь на данных литературных источников и результатах прошлых собственных исследований, показать значимость дефицита лизоцима в патогенезе COVID-19. Актуальность исследования обусловлена планетарным масштабом распространения коронавирусной инфекции, появлением SARS-CoV-2 с новыми агрессивными признаками, трудностями их лечения и предупреждения. Установлена анатомо-функциональная связь защитных механизмов лизоцима, мукополисахаридов гистогематических барьеров с сохранением иммунного, биохимического и тканевого гомеостаза. Утрата лизоцима, обладающего генетически детерминрованной ферментативной специфичностью, способствует развитию повреждающих процессов иммунного, биохимического и тканевого характера с манифестацией во все органы и системы организма. Предложено включение экзогенного лизоцима в базовую терапию и профилактику COVID-19.

Ключевые слова: новая коронавирусная инфекция, COVID-19, SARS-CoV-2, лизоцим, профилактика, лечение

Для цитирования: Дорофейчук В.Г., Шер С.А. Концепция возникновения новой коронавирусной инфекции. Педиатрическая фармакология. 2020;17(6):547-551. doi: 10.15690/pf.v17i6.2203

В течение многих лет было известно о постоянной циркуляции среди населения большого семейства РНКсодержащих вирусов и участии в структуре острых респираторных вирусных инфекций коронавирусов четырех типов, вызывающих поражение верхних дыхательных путей легкой и средней тяжести с крайне редким летальным исходом.

В конце 2019 г. появился новый коронавирус, первоначально получивший название 2019-nCoV, затем переименованный в SARS-CoV-2. Вспышка началась в Китае. Источником инфекции является больной человек, в том числе в инкубационном периоде. Болезнь может развиваться в течение двух недель от бессимптомной или легкой формы до тяжелого острого респираторного синдрома с дыхательной недостаточностью, лихорадкой, кашлем, одышкой, тахикардией, полиорганной недостаточностью, летальным исходом. С самого начала вспышки шли сообщения о том, что SARS-CoV-2

\section{Valentina G. Dorofeychouck, Stella A. Sher}

Research Institute of Pediatrics and Children's Health in "Central Clinical Hospital of the Russian Academy of Sciences", Moscow, Russian Federation

\section{Concept of emergence of a new coronavirus infection}

This report presents a brief review of literature and the authors' concept of the emergence of the novel coronavirus 19 infection. The purpose of the work is to show the significance of lysozyme deficiency in the pathogenesis of COVID-19 based on data from literature sources and the results of the authors' past studies. The relevance of the study is due to the planetary scale of the spread of coronavirus infection, the appearance of SARS-CoV-2 with new aggressive signs, the difficulties of their treatment and prevention. Anatomo-functional connection of protective mechanisms of lysozyme, mucopolysaccharides of histohaematic barriers with preservation of immune, biochemical and tissue homeostasis is established. The loss of lysozyme, which has genetically determined enzymatic specificity, contributes to the development of damaging processes of immune, biochemical and tissue nature with manifestation in all organs and systems of the body. Inclusion of exogenous lysozyme in basic therapy and prophylaxis COVID-19 is proposed. Keywords: new coronavirus infection, COVID-19, SARS-CoV-2, Iysozyme, prevention, treatmentq12

For citation: Dorofeychouck Valentina G., Sher Stella A. Concept of emergence of a new coronavirus infection. Pediatricheskaya farmakologiya - Pediatric pharmacology. 2020;17(6):547-551. doi: 10.15690/pf.v17i6.2203 
поражает легкие, преимущественно нижние отделы в виде воспалительных процессов в альвеолах, диффузных поражений интерстиция, с развитием фиброза, пневмосклероза.

Широкое, планетарного масштаба распространение коронавирусной инфекции, загадочное появление SARSCoV-2 с новыми агрессивными признаками, которые в полной мере реализуются, прежде всего, у старшего поколения, трудности их лечения и предупреждения ставят в разряд актуальных, первоочередных задач установление механизмов возникновения и развития болезни, факторов, способствующих тяжести патологического процесса и, соответственно, подходов к патогенетически обоснованной терапии и профилактике.

С нашей точки зрения, глубокие патоморфологические изменения в легких, имеющие место при COVID-19, но нехарактерные для типичной пневмонии, являются "зеркальным отражением" химического воздействия на органы дыхания. Примером химического поражения легких являются патоморфологические изменения в легочной ткани, возникающие при длительном вдыхании кремниевой пыли. При этом реализуется способность силанольных групп (SiOH), расположенных на поверхности кристаллов кремния, адсорбировать белки оболочек фагоцитов с последующим повреждением легочной ткани: лимфостазом, нарушением кровообращения, воспалительными и атрофическими процессами в альвеолах, формированием фиброза, разрастанием соединительной ткани с нарушением структуры и физиологически необходимой функции легких.

Разница лишь в сроках реализации агрессивных свойств SARS-CoV-2 и кремниевой пыли. Только вирус, обладающий определенной тропностью, способен в короткие сроки доставить патоген в легочную ткань.

Система дыхания является входными воротами для SARS-CoV-2 и служит ареной для тесного их взаимодействия. Никакой другой путь проникновения вируса в организм не сравнится с респираторным трактом по масштабам распространения, по объему и скорости транспорта в периферические органы и ткани. Это связано с большой поверхностью контакта альвеолярной ткани с внешней средой, с физиологически необходимой скоростью воздухообмена, с анатомо-функциональной связью с организмом в целом.

Высокая агрессивность SARS-CoV-2 не может быть случайной. Правомерно предположить, что новые свойства SARS-CoV-2 - это результат изменения его генетического кода. Спонтанные мутации в целом не носят направленного характера. Они могут появляться в результате каких-либо процессов (ультразвук, радиация и т.п.). В естественных условиях частота мутирования не настолько велика, чтобы в исторически короткие сроки кардинально изменить повреждающие свойства вирусов, повлекшие за собой трудности терапии. Лишь индуцированный мутагенез способен создать вирус с заведомо заданными признаками: в короткие сроки вызывать тяжелые поражения легочной ткани, как при вдыхании химических соединений. Новые признаки в процессе клеточного деления закрепляются и воспроизводятся.

Какого бы происхождения ни был SARS-CoV-2 (спонтанного или индуцированного), он уже есть и беспрепятственно распространяется по всей планете. Поэтому необходимо не только преградить ему контакт с населением, но и адекватно ответить на его агрессию, что не отменяет строжайшее соблюдение личной гигиены и самоизоляции.
Любая болезнь - это результат нарушения сбалансированности агрессивных и защитных механизмов. При взаимодействии человека с окружающим миром в потоке агрессивных воздействий общей и неизменной является реакция организма в виде нарушения ферментных систем. Наиболее чувствительным является универсальный фермент мурамидаза - лизоцим.

В литературе неоднократно поднимался вопрос об истинном биологическом назначении лизоцима. Еще в 1940 г. известный американский микробиолог Джонсон писал: “Фермент, обнаруживаемый столь широко от вирусов до высших животных и человека на всех этапах эволюции, должен иметь фундаментальное биологическое значение, и курьезом является тот факт, что он так долго находится в пренебрежении у физиологов".

К настоящему времени накоплен огромный материал, свидетельствующий о тесной анатомо-функциональной связи лизоцима с иммунной системой и метаболическими процессами, его роли в обеспечении естественной толерантности организма к генетически чужеродным агентам.

Наиболее высокая концентрация лизоцима определяется в жизненно важных органах и системах, где организм более всего нуждается в защите иммунобиологического постоянства, где наиболее интенсивно протекают процессы метаболизма, где с повышенной скоростью происходит обновление макромолекул.

Ключевое значение в сохранении общебиологического гомеостаза имеют гистогематические барьеры между кровью и тканевой жидкостью. Наряду с регуляцией обменных процессов они выполняют функцию физиологического “фильтра", препятствующего переходу чужеродных агентов из крови в ткани и из тканей в кровь.

На пути вдыхаемого воздуха функционируют гематосаливарный и гематопульмональный барьеры. Находясь в неразрывной связи с общей системой гистогематических барьеров, они являются "заслоном" для проникновения потенциально опасных агентов в периферическую капиллярную сеть.

Основным структурным элементом гистогематических барьеров является эндотелиальный слой клеток, выстилающий внутреннюю поверхность капилляров. В цитоплазме клеток эндотелия располагается большое количество органелл - лизосом с высокой концентрацией лизоцима и других гидролаз, выполняющих основную роль в клеточном метаболизме.

Эндогенный лизоцим, обладая широким спектром биологических возможностей, обеспечивает иммунобиологический, биохимический и тканевой гомеостаз. С одной стороны, он препятствует контакту чужеродных макромолекул с иммунокомпетентными клетками крови, с другой - нейтрализует избыточное накопление повреждающих компонентов иммунного ответа и токсических метаболитов путем дезинтеграции иммунных комплексов, инактивации аутоантигенов, имеющих мукополисахаридный состав. Лишь лизоцим, обладающий эволюционно запрограммированной высокой специфичностью к мукополисахаридам, может препятствовать накоплению непереваренного субстрата.

Благодаря антиоксидантным, антигистаминным, антиацидотическим, антиадгезивным свойствам лизоцим способствует укреплению цитоплазматических мембран, поддерживает физиологически необходимую проницаемость защитных барьеров, препятствует тромбообразованию, проникновению чужеродных агентов во внутреннюю среду организма. 
Важным условием сохранения тканевого гомеостаза является элиминация из организма аномальных белков и других чужеродных субстанций. Эту функцию в составе эндотелиального слоя клеток выполняют лизосомы, которые переваривают промежуточные продукты обмена. Особого внимания заслуживают уникальные свойства клеточных лизосом: самопереваривание собственной оболочки сопровождается самоуничтожением. Полученные вещества и энергия используются другими клетками.

Патоморфологические изменения при COVID-19, связанные с лизосомными накоплениями негидролизованного субстрата, являются пусковым звеном структурно-функциональных нарушений эндотелиального слоя капиллярной сети.

В условиях дефицита лизоцима неинактивированные аутоантигены запускают развитие аутоиммунных и иммунокомплексных реакций. К повреждению защитного барьера приводит и накопление токсических метаболитов, вызывающих метаболический ацидоз, нарушение скорости свободнорадикального окисления липидов, дестабилизацию клеточных мембран, развитие внутрисосудистых воспалительных и деструктивных процессов, повышение проницаемости защитного барьера. При этом нарушается кровоснабжение, снижается скорость кровотока, усиливаются процессы тромбообразования, наблюдаются уплотнение плевры, средостения, интерстициальной ткани с выходом экссудата в просвет альвеол, формирование фиброза, разрастание соединительной ткани, увеличение мертвого пространства и нарастание дыхательной недостаточности (см. рисунок).

Системный характер структурно-функциональных нарушений от первых признаков до манифестации патологического процесса с частой локализацией в легких свидетельствует об утрате защитных функций лизоцима. Подтверждением значимости дефицита лизоцима в патогенезе COVID-19 являются данные о возникновении и тяжести течения болезни у лиц старшего возраста, обусловленных снижением лизоцима в онтогенезе, в том числе в связи с угасанием репродуктивной функции.

Тесно взаимодействуя с иммунными и метаболическими процессами, лизоцим обеспечивает сохранение генетически чужеродного внутриутробного ребенка в организме матери. Об этом свидетельствует высокая концентрация лизоцима в репродуктивных органах на всех этапах репродуктивного процесса, на всех этапах филогенеза.

Преодолевая генетическую несовместимость плода и тканей материнского организма, лизоцим обеспечивает иммунологическую толерантность в системе "мать-плод". По мере увеличения срока беременности при нарастании антигенной нагрузки лизоцимная активность сыворотки крови матери повышается, а в послеродовом периоде снижается, оставаясь в пределах возрастной физиологической нормы.

При угасании репродуктивной функции лизоцимная активность неуклонно снижается и к 70-75 годам, достигая минимальных значений, уже не повышается. Организм становится доступным для повреждающего влияния различных негативных факторов. А если учесть истощение лизоцима в онтогенезе под влиянием агрессивного воздействия окружающего мира, включая стрессовые ситуации и накопление антигенной нагрузки к старости, то становится понятно, почему население старшего возраста наиболее подвержено COVID-19 с тяжелым течением и нередко летальным исходом. Именно в этой возрастной группе факторы агрессии превышают потенциальные возможности защитных систем организма.

В условиях физиологически нормальной жизнедеятельности организма очищение внутренней среды функционально связано с эволюционно запрограммированной выделительной системой, в которую входят мочевыводящая, пищеварительная, дыхательная системы и кожные покровы. Общеорганизменные структурнофункциональные нарушения отражаются и на состоянии выделительной системы.

Рисунок. Схема возникновения новой коронавирусной инфекции COVID-19

Figure. Scheme of the emergence of a new coronavirus infection COVID-19

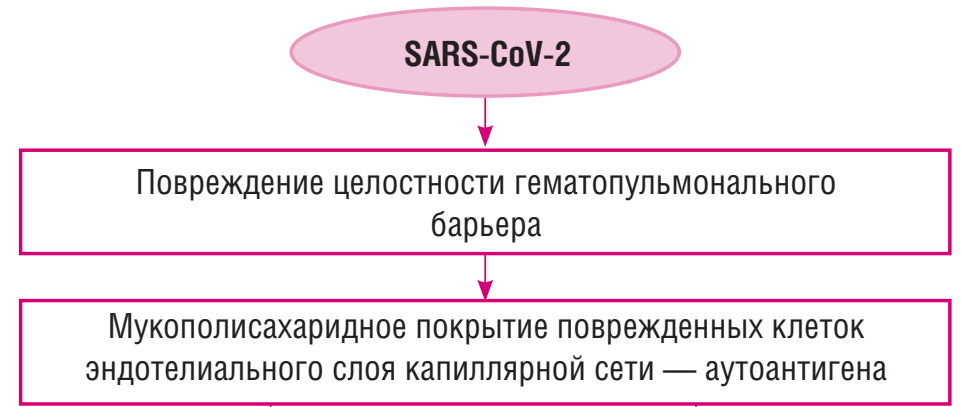

- Достаточное содержание в лизосомах внутриклеточного лизоцима обеспечивает инактивацию аутоантигенов путем фрерментсубстратного взаимодействия лизоцима с мукополисахаридами, входящими в состав оболочек антигенов

- Лизосомы ответственны и за гидролиз, и за утилизацию продуктов их расщепления

- Внедрение SARS-CoV-2 ограничивается бессимптомным взаимодействием
- В условиях десрицита лизоцима беспрепятственное накопление негидролизованного субстрата, являющегося постоянным источником аутоантигенов, сопровождается нарушением иммунитета, метаболического и тканевого гомеостаза

- Воспалительно-дистрофические изменения эндотелиального слоя капиллярной сети в короткие сроки приводят к манифестации системного поражения с нарушением структуры и жизненно важных функций всех органов и систем организма 
Через мочевыводящую систему выделяется 75\% жидких продуктов обмена, кроме высокомолекулярных белков. При COVID-19 физиологически нормальная фильтрационная способность почек не обеспечивает удаление структурно-сложных белково-полисахаридных комплексов, что сопровождается дисфункцией почек. Какая-то часть поврежденных компонентов выводится через пищеварительную систему, о чем свидетельствует появление тошноты, рвоты, диареи у части больных COVID-19.

Очищение внутренней среды организма происходит и через кожные покровы, что проявляется возникновением мелкоточечной сыпи, петехий, пятен, «ковидных пальцев" и т.д.

Дыхательная система с тяжелым поражением легких не только не справляется с выделительной функцией, она препятствует полноценной оксигенации организма и перестает быть "заслоном" для транспорта вируса в периферическую капиллярную сеть.

SARS-CoV-2 проникает во все органы и ткани, что сопровождается шоком и полиорганной недостаточностью.

Представленные данные о системном характере патоморфологических изменений при COVID-19 свидетельствуют о появлении новых агрессивных свойств у коронавируса и о значимости дефицита лизоцима в патогенезе их реализации.

Химический характер повреждений при COVID-19 остается скрытым под маской вируса и поэтому первая помощь ограничивается симптоматической терапией. С нашей точки зрения, лишь неотложные мероприятия, направленные на очищение внутренней среды организма, как это требуется при острых химических отравлениях, могут прервать, остановить прогрессирование разрушительного процесса.

Как было указано выше, эндогенный лизоцим, участвуя в регуляции иммунных и метаболических процессов, занимает важнейшее место в интегрированной деятельности специализированных систем организма. Обладая высокой специфичностью, эндогенный лизоцим, инактивируя аутоантигены, не допускает накопления негидролизованного субстрата, а также может растворять уже накопленные склеенные структуры из лизосом. Никакой другой препарат, обладающий свойствами лизоцима (антиоксидантные, антиадгезивные, антитоксические и т.д.) не может воспроизвести специфичность его ферментативной функции. Поэтому назначение экзогенного лизоцима должно лежать в основе базовой терапии COVID-19.

В настоящее время экзогенный лизоцим включен в состав многих комплексных препаратов. Он повышает эффективность их применения в терапии различных заболеваний.

Общебиологическая функция лизоцима по освобождению организма лишь от избыточного накопления повреждающих компонентов иммунного ответа и токсических метаболитов открывает новые возможности для эфферентной медицины. Лизоцим используется как в виде монопрепарата, так и в комплексе с ферментами и другими органическими и неорганическими соединениями, а также для обогащения продуктов лечебного питания, главным образом, в детской практике.

Особого внимания заслуживает сублингвальный прием дотационной доставки экзогенного лизоцима: быстро всасывается, в короткие сроки способствует восстановлению общеорганизменного гомеостаза.

Для предупреждения коронавирусной инфекции целесообразно применять лизоцим в группах повышенного риска, которыми являются:

1) персонал медицинских учреждений;
2) люди, находящиеся на карантине;

3) население старшего возраста в очагах с высокой заболеваемостью COVID-19;

4) беременные женщины с низким уровнем лизоцима по эпидпоказаниям.

К группам риска относятся больные диабетом. Нами установлено снижение лизоцима в секрете ротовой полости, сыворотке крови на фоне выделения его с мочой у больных диабетом. Дефицит лизоцима коррелировал с тяжестью и длительностью заболевания, с избыточным накоплением повреждающих компонентов иммунного ответа (ЦИК), с метаболическим ацидозом, с нарастанием концентрации продуктов перекисного окисления липидов и процессов адгезии и гиперагрегации тромбоцитов.

Для выявления возможных негативных последствий от COVID-19 необходимо предусмотреть активный патронаж лиц, перенесших COVID-19 и заразившихся COVID-19 без клинических проявлений инфекции.

Системный подход к базовой терапии и профилактике COVID-19, предусматривающий в соответствии с данной концепцией ускоренное выведение из организма SARSCoV-2, а также включение экзогенного лизоцима, позволит снизить уровень заболеваемости, глубину и тяжесть поражения организма и, соответственно, исключить COVID-19 из списка причин смертности среди населения.

Широкое внедрение экзогенного лизоцима, лизоцимсодержащих препаратов и продуктов лечебного питания в комплексную терапию и профилактику COVID-19 расширит превентивные и реабилитационные возможности медицины и окажет положительное влияние на укрепление здоровья населения. Назначение экзогенного лизоцима, обеспечивая иммунный и биохимический гомеостаз, остановит прогрессирование болезни на любом этапе. Не исключено, что тропное повышение концентрации лизоцима в первичном очаге воспаления позволит добиться регрессии фиброза, особенно на ранних этапах его формирования.

Значимость эндогенного лизоцима в защите от коронавирусной инфекции подтверждается отсутствием COVID-19 у новорожденных, тесно контактирующих с зараженными мамами. Высокая лизоцимная активность в тканях плаценты, околоплодных водах, сыворотке крови плода, секрете ротовой полости новорожденных, а также в грудном молоке матери, особенно в молозиве, обеспечивает защиту плода и новорожденного от агрессивного внедрения COVID-19. Вполне оправданно указание В03 не препятствовать грудному вскармливанию. Следует, однако, помнить, что грудное молоко может быть использовано в качестве донорского только при условии отсутствия у матери других заболеваний (гепатит и др.).

Наиболее целебным является нативное молоко, содержащее большое количество макрофагов, продуцирующих лизоцим. Защитные свойства сохраняются при замораживании молока. При пастеризации отмечается снижение концентрации лизоцима. Кипячение молока приводит к полной утрате уникальных свойств грудного молока.

Примером тяжелого поражения легочной ткани в условиях дефицита лизоцима являются гистопатологические изменения в легких у пациента с COVID-19 - 72-летнего мужчины с диабетом и гипертонией в анамнезе, с лихорадкой, кашлем, быстро прогрессирующей дыхательной недостаточностью. Несмотря на противовирусную терапию, нестабильность дыхания и гемодинамики продолжались, и пациент умер через 3 нед после постановки диагноза. Из протокола вскрытия: гистопатологическое исследование тканей биопсии легкого выявило повреж- 
дение эпителиальных клеток с десквамацией в альвеолы, диффузные альвеолярные повреждения, реактивную гиперплазию, утолщение плевры, увеличение средостения, лимфоузлов, рыхлый интерстициальный фиброз, внутриальвеолярные экссудаты с фиброзом, воспалительные инфильтраты. Воспаление - маркер аутоиммунных реакций. Выявлена выраженная экспрессия антител на альвеолярных эпителиальных клетках. Напротив, экспрессия вирусного белка была минимально обнаруживаемой на кровеносных сосудах или в интерстициальных областях между альвеолами.

Таким образом, в кратком обзоре на основании литературных источников и результатов собственных прошлых исследований представлена авторская концеп- ция возникновения новой коронавирусной инфекции. Показано, что дефицит лизоцима, обладающего генетически детерминрованной ферментативной специфичностью, способствует развитию повреждающих процессов иммунного, биохимического и тканевого характера с манифестацией во все органы и системы организма. Предложено включение экзогенного лизоцима в базовую терапию и профилактику COVID-19.

\author{
ORCID И EDRID \\ В.Г. Дорофейчук \\ https://edrid.ru/authors/201.d44cc.html \\ C.A. Шep \\ https://orcid.org/0000-0003-4364-2604
}

\section{СПИСОК ЛИТЕРАТУРЫ / REFERENCES}

1. Баранов А.А., Дорофейчук В.Г. Лизоцим: теория и практика. - М.; Н. Новгород; 1999. - 127 с. [Baranov AA, Dorofeichuk VG. Lizotsim: teoriya i praktika. Moscow; Nizhnii Novgorod; 1999. 127 p. (In Russ).] 2. Баранов А.А., Дорофейчук В.Г. Лечебное питание при нарушениях защитных механизмов пищеварительного тракта у детей // Педиатрия. - 1984. - № 6. - C. 73-75. [Baranov AA, Dorofeichuk VG. Lechebnoe pitanie pri narusheniyakh zashchitnykh mekhanizmov pishchevaritelınogo trakta u detei. Pediatriya. 1984;(6):73-75. (In Russ).]

3. Бородулин В.И. Пневмокониозы: справочник практического врача / под ред. проф. А.И. Воробьёва. - М.: Медицина; 1983. - C. 106-108. [Borodulin VI. Pnevmokoniozy: spravochnik prakticheskogo vracha. Pod red. prof. A.I. Vorob'eva. Moscow: Meditsina; 1983. pp. 106-108. (In Russ).]

4. Бухарин О.В., Васильев Н.В. Лизоцим и его роль в биологии. Томск; 1974. - 208 c. [Bukharin OV, Vasilsev NV. Lizotsim i ego rol' $v$ biologii. Tomsk; 1974. 208 p. (In Russ).]

5. Васильева З.Ф., Шабалин В.Н. Иммунологические основы акушерской патологии. - М.: Медицина; 1984. - 192 с. [Vasilıeva ZF, Shabalin VN. Immunologicheskie osnovy akusherskoi patologii. Moscow: Meditsina; 1984. 192 p. (In Russ).]

6. Гистология. Гистогематические барьеры. [Gistologiya. Gistogematicheskie bar'ery. (In Russ).] Доступно по: https:// www. referat911.ru/Medicina/gistologiya-gistogematicheskie-barery/3082882680874-place1.html. Ссылка активна на 01.06.2020.

7. Дорофейчук В.Г., Волков А.И., Карасёва Г.Н. и др. Способ получения кисломолочного продукта. - Авторское свидетельство № 1091380. - 1984. [Dorofeichuk VG., Volkov Al., Karaseva GN, et al. Sposob polucheniya kislomolochnogo produkta. Avtorskoe svidetel'stvo № 1091380. 1984. (In Russ).]

8. Дорофейчук В.Г., Комарова Л.Г. Способ диагностики обострения болезни желудка и 12-перстной кишки. - Авторское свидетельство № 1128909. - 1984. [Dorofeichuk VG, Komarova LG. Sposob diagnostiki obostreniya bolezni zheludka i 12-perstnoi kishki. Avtorskoe svidetel'stvo № 1128909. 1984. (In Russ).]

9. Дорофейчук В.Г., Ершова А.И., Медяник Н.И. Способ предупреждения невынашивания беременности. - Авторское свидетельство № 1297863. - 1986. [Dorofeichuk VG, Ershova Al, Medyanik NI. Sposob preduprezhdeniya nevynashivaniya beremennosti. Avtorskoe svidetel'stvo № 1297863. 1986. (In Russ).]

10. Дорофейчук В.Г., Салина Е.В., Маянская И.В. и др. Способ прогнозирования частых инфекционных заболеваний у детей. Авторское свидетельство № 1332229. - 1987. [Dorofeichuk VG, Salina EV, Mayanskaya IV et al. Sposob prognozirovaniya chastykh infektsionnykh zabolevanii u detei. Avtorskoe svidetel'stvo № 1332229. 1987. (In Russ).]

11. Дорофейчук В.Г. Механизмы защитной функции лизоцима фундаментальное и прикладное значение // Нижегородский медицинский журнал. - 1996. - № 2. - C. 9-13. [Dorofeichuk VG. Mekhanizmy zashchitnoi funktsii lizotsima, fundamentalınoe i prikladnoe znachenie. Nizhegorodskii meditsinskii zhurnal. 1996;(2):913. (In Russ).]

12. Дорофейчук В.Г., Толкачева Н.И., Шер С.А. Общебиологическая функция лизоцима пищеварительных секретов в обеспечении естественной толерантности организма к генетически чуже- родным агентам // Российский журнал гастроэнтерологии, гепатологии, колопроктологии. Приложение № 36. Материалы XVI Российской гастроэнтерологической недели, 11-13 октября 2010 г. - 2010. - T. 20. - № 5. - C. 121. [Dorofeichuk VG, Tolkacheva NI, Sher SA. Obshchebiologicheskaya funktsiya lizotsima pishchevaritel,nykh sekretov v obespechenii estestvennoi tolerantnosti organizma k geneticheski chuzherodnym agentam. Rossiiskii zhurnal gastroenterologii, gepatologii, koloproktologii. Prilozhenie № 36. Materialy XVI Rossiiskoi gastroenterologicheskoi nedeli, 11-13 oktyabrya 2010 g. 2010;20(5):121. (In Russ).]

13. Дорофейчук В.Г., Толкачева Н.И., Шкенёва Л.Н. и др. Лизоцим слюны - индикатор антигенной нагрузки организма // Российский журнал гастроэнтерологии, гепатологии, колопроктологии. Приложение № 38. Материалы XVII Российской гастроэнтерологической недели. - 2011. - Т. 21. - № 5. - C. 179. [Dorofeichuk VG, Tolkacheva NI, Shkeneva LN, et al. Lizotsim slyuny - indikator antigennoi nagruzki organizma. Rossiiskii zhurnal gastroenterologii, gepatologii, koloproktologii. Prilozhenie № 38. Materialy XVII Rossiiskoi gastroenterologicheskoi nedeli. 2011;21(5): 179. (In Russ).]

14. Дорофейчук В.Г., Чупров А.Д. Свойство эндогенного лизоцима нейтрализовать влияние антигенных факторов на живой организм. - Диплом на открытие № 435. - 2012. [Dorofeichuk VG, Chuprov AD. Svoistvo endogennogo lizotsima neitralizovat' vliyanie antigennykh faktorov na zhivoi organizm. Diplom na otkrytie № 435 . 2012. (In Russ).]

15. Лизоцим. [Lizotsim. (In Russ).] Доступно по: https://www.xumuk. ru/encyklopedia/2319.html. Ссылка активна на 01.06.2020.

16. Профилактика, диагностика и лечение новой коронавирусной инфекции (COVID-19). Временные методические рекомендации. Версия 5. (08.04.2020). [Profilaktika, diagnostika i lechenie novoi koronavirusnoi infektsii (COVID-19). Vremennye metodicheskie rekomendatsii. Versiya 5. (08.04.2020). (In Russ).] Доступно по: https://стопкоронавирус.рф/ai/doc/114/attach/vremennie_mr_ COVID-19_versiya_5.pdf. Ссылка активна на 01.06.2020.

17. Рансбергер К., Ной С. Энзимы и энзимотерапия. - Мюнхен: Медицинское общество по изучению энзимов; 1994. - 243 с. [Ransberger K, Noi S. Enzimy i enzimoterapiya. Myunkhen: Meditsinskoe obshchestvo po izucheniyu enzimov; 1994. 243 p. (In Russ).]

18. Corti G., Paradisi F. Pathogenic mechanisms responsible for producing a secondary immunodeficiency state. J Chemother. 1994;6 Suppl 3:6-10.

19. Dorofeychouk VG, Sher SA. Lysozyme theoretical and practical. In: The Second International Conference of Russian speaking Medical doctors, stomatologists and biologists. New York City, USA; 1998. p. 45. 20. Elsevier's free health and medical research on the novel coronavirus (SARS-CoV-2) and COVID-19. // Available online: https:// www.elsevier.com/connect/coronavirus-information-center. Accessed on June 2, 2020.

21. Jolles R., Berniod I. Lysozyme. In: Lysozyme Conference Arden House 1972. Osserman EF, Canfield RE, Beychok S, eds. New York: Academic Press; 1974. pp. 31-46.

22. Kivinen A, Tarpila S, Kiviluoto T, et al. Milk and egg phospholipids act as protective surfactants against luminal acid in Necturus gastric mucosa. Aliment Pharmacol Ther. 1995;9(6):685-691. doi: 10.1111/ j.1365-2036.1995.tb00439.x 